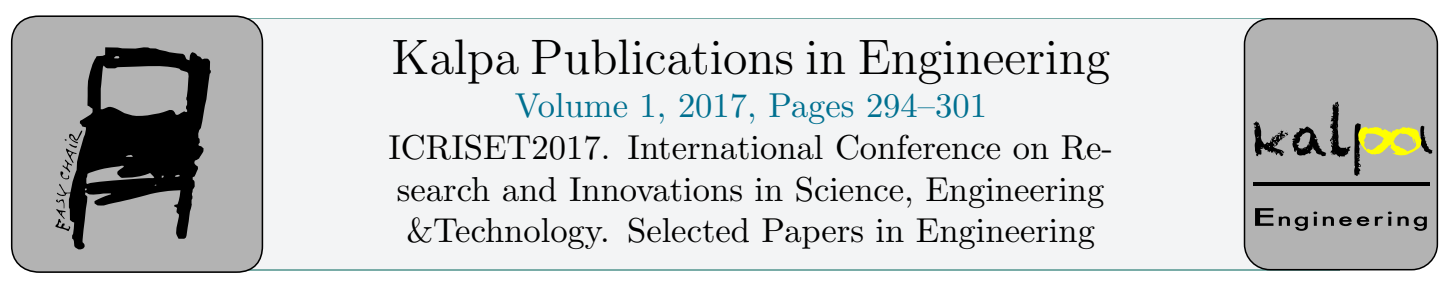

\title{
Design and Analysis of Solid and Cross-Drilled Disc Brake Rotors
}

\author{
Jimit G. Vyas ${ }^{1}$, Prof. M. J. Zinzivadia ${ }^{2}$, Prof. M. I. Kathadi ${ }^{3}$ \\ ${ }^{1}$ Research Scholar, ${ }^{2}$ Associated Professor, ${ }^{3}$ Associated Professor \\ ${ }^{1,2,3}$ Mechanical Engineering Department, BVM Engineering College, Anand, India \\ ${ }^{1}$ jimitvyasl@gmail.com, ${ }^{2}$ mjzinzuvadia@bvmengineering.ac.in, \\ ${ }^{3}$ mikathadiebvmengineering.ac.in
}

\begin{abstract}
In this paper analysis of automotive disc brake rotor is carried out with the help of ANSYS 17.1 Academic software. Disc brakes operate on the principle of friction by converting the kinetic energy of the vehicle into heat energy at the contact between disc and pads. The main objective of a disc brake rotor is to store this generated heat energy and dissipate it into the environment as soon as possible. This heat rapidly increases the temperature of the disc at the rubbing surface, resulting in thermal stresses in the components of the brake. Thermal behavior of solid and cross drilled brake disc rotors is studied. For numerical analysis commercially available tool ANSYS is used to determine temperature distribution in the disc.
\end{abstract}

\section{Introduction}

The purpose of the automobile brake system is to slow down or completely stop the vehicle within a reasonable amount of time duration. In order to achieve this purpose, brake system must be reliable to provide better control to the driver of the vehicle. Any automobile vehicle contains kinetic energy due to its speed and motion. Higher the speed of the vehicle implicates much higher kinetic energy of the vehicle as the kinetic energy is directly proportional to the square of this speed. Most of the available braking system uses the principle of friction to convert the said kinetic energy into heat energy. The braking system must store and dissipate all of this heat into the surrounding environment before subsequent braking applications in order to achieve good braking efficiency.

\subsection{Disc brakes}

Frederick William Lanchester patented disc brakes in 1902 but they were not used. Commercial use of these type of brake system started in the early 1950s. This brake system consists of the rotor made of cast iron (1) (or ceramic) mounted on the wheel hub (Figure 1). For braking 
action brake pads made of frictional material are forced on the rotor. Pads are forced with help of hydraulic piston cylinder assembly which is machined inside the caliper. The number of pistons inside the caliper can vary from 2 to 4 depending on the requirement of the force (2).

The brake rotor is one of the important parts of the disc brake system. The heat energy produced by the braking action is absorbed in the brake disc rotor and as mentioned earlier, it is important to dissipate this heat before subsequent braking applications in order to avoid thermal distortion of the rotor. Various designs of the disc brake are available. Some disc brakes are manufactured as a solid C.I. cylinder where others have holes or vents on them. They improve heat dissipation from the rotor by increasing the surface area available to transfer heat. Some designs have vanes between two rubbing surfaces. These vanes not only increases surface area but also provides higher air flow at the high rotational speed improving heat transfer.

Generally, the performance of the brakes is reduced when the vehicle travels from the water puddles, as water film is created between disc and pads. Cross- drilled design helps in quick removal of the water film improving performance in short duration. In spite of this advantage, the cross-drilled disc is not used sometimes because the holes become regions of high-stress concentration. Eventually, results in cracking the rotor.

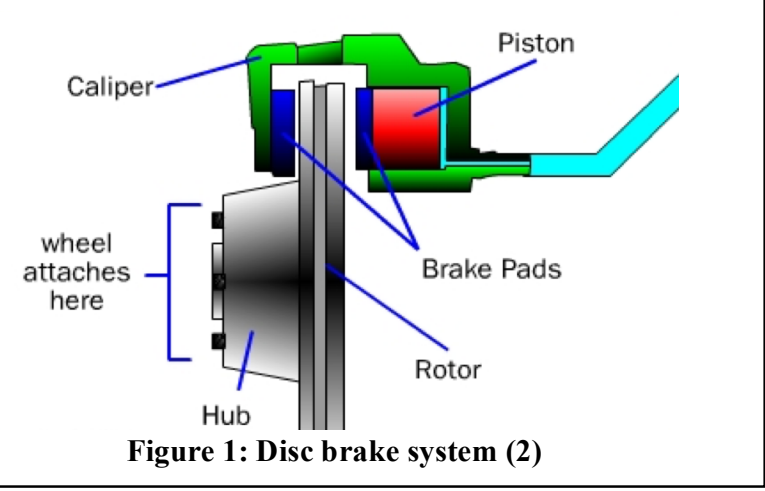

\subsection{Reasons of disc brake failure}

Disc brakes are likely to fail as they store all the heat energy that gets produced during the braking operation before eventually dissipating it into the surrounding atmosphere. These failures can cause partial or full failure of the disc brake rotor The various types of disc brakes failures are listed below.

- Thermo-Mechanical distortion:

- Cracking

- $\quad$ Brake fading

\section{Literature survey}

\subsection{Material Selection}

Brake rotor can be made of different materials like cast iron, aluminum, MMC (Metal Matrix Composite), ceramics etc. All materials have their advantages and disadvantages. M.A. Maleque, S.Dyuti, and M.M. Rahman (3) compared these materials for most of the properties of the 
brake rotor material. In that study material selection methods for design and application of brake rotor were developed. Properties of the brake disc or rotor were considered for initial screening of materials using Ashby's material selection chart. After that digital logic method was used to

calculate performance index for shortlisted materials. As a result, two materials were selected with highest two performance index. They are AMC (Al-Cu alloy reinforced with $20 \% \mathrm{SiC}$ ) and Grey Cast Iron.

\subsection{Heat Transfer Modes}

In 1975 Limpert (4) (5) (6) performed experiments on disc brakes and concluded that contribution of radiation in overall heat dissipation is less than $5 \%$ of the total heat dissipation at the normal braking conditions. Limpert (4) also concluded that at higher temperatures the contribution of radiation increases and becomes as much as $33 \%$ of the total heat transfer.

Voller (7) has also done experimental analysis on a ventilated disc brake rotor and studied the contribution of modes of heat transfer. The author concluded that conduction was essentially independent of the speed of the vehicle and its significance is higher at lower speeds.

It was also suggested that radiation is independent of speed whereas convection increases strongly with rotational speed.

The experiment was done by Voller (7) at a temperature of $600^{\circ} \mathrm{C}$ and a speed of $150 \mathrm{rpm}$. He measured the contribution of conduction $18 \%$, convection $39 \%$ and radiation $43 \%$. Then at a higher speed of $450 \mathrm{rpm}$, the contribution of convection increased to $57 \%$ and the other two modes are essentially independent of speed.

\subsection{Mass flow rate}

Dr. Thundil (8) carried out CFD study of the disc brake rotor passage for different speed and observed mass flow rate. From the study, he concluded that mass flow rate in ventilated disc brake rotor is the function of the speed. As the rotational speed of the disc is increased, the mass flow rate in the rotor passage increases. Dr. Thundil also concluded that design of the rotor should not be only based on the required heat transfer coefficient but it should also be designed considering uniform heat dissipation from the surface of the rotor.

Ali Belhocine (9) (10) carried out CFD analysis for the thermal behavior of the ventilated disc brake rotors using computing code ANSYS. Ali Belhocine (9) derived the relation of the heat transfer coefficient on various surfaces to the speed of the vehicle. He concluded that with a decrease in speed, the value of heat transfer coefficient at every surface of the disc rapidly decreases. For low rotational speeds, convection is closed to natural convection.

\section{General calculations for hydraulic disc brake}

In order to calculate input parameter for the study of disc brake system, a typical automobile vehicle is taken into consideration. Specific dimensions of the vehicle are measured. Considering following measured data further calculations are carried out. Table 1 includes major datasets which will be taken as constant through the study. There are other parameters like time which are taken as a variable in the study. 


\begin{tabular}{|l|l|}
\hline Mass of Vehicle, $M_{v}$ & $1200 \mathrm{~kg}$ \\
\hline Diameter of caliper piston & $0.027 \mathrm{~m}$ \\
\hline Diameter of Master cylinder & $0.02 \mathrm{~m}$ \\
\hline Rolling friction coefficient, $\mu_{r}$ & 0.04 \\
\hline Mechanical Advantage (leverage) & 6 \\
\hline Coefficient of friction between wheel and wet road surface & 0.45 \\
\hline Co-efficient of friction between wheel and dry road surface, $\mu_{r w}$ & 0.8 \\
\hline Diameter of wheel & $0.508 \mathrm{~m}$ \\
\hline
\end{tabular}

Table 1: Constants and assumptions

\subsection{Optimum braking condition}

This condition is the best braking condition in which applied pedal force creates maximum pressure force at the contact of disc and pad at which the disc slides without locking of the wheel. Maximum braking force or minimum wheel locking force,

$$
\mathrm{F}_{\max }=\mu_{r w} \times \mathrm{M}_{\mathrm{v}} \times \mathrm{g}=9417.6 \mathrm{~N}
$$

\subsection{Calculation of braking time}

The braking process starts with the application of force on the brake pedal with leverage.

So fluid in the master cylinder gets pressurized. This pressure force acts on the caliper side cylinders. Caliper in the selected vehicle has two piston arrangement usually 2 to 4 pistons can be accommodated inside of the caliper.

Pressure in master cylinder,

Friction force on each disc,

$$
P_{c}=\frac{\text { Padel Force } \times \text { Leverage }}{\text { Master cylinder area }}
$$

$$
\mathrm{F}_{\mathrm{e}}=\mu_{\mathrm{d}} \times \mathrm{P}_{\mathrm{c}} \times(2 \times \text { Area of caliper cylinder })
$$

Now this friction force provides braking torque to wheel and then this braking torque is converted into the braking force which can be calculated by the following equation.

Brake force by each disc,

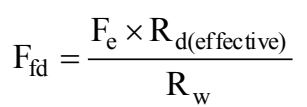

In addition to the braking force exerted by braking system addition rolling friction also acts against the motion of the vehicle.

Rolling friction force,

$$
\mathrm{F}_{\mathrm{fr}}=\mu_{\mathrm{r}} \times \mathrm{M}_{\mathrm{v}} \times \mathrm{g}
$$

Now total braking force is the summation of forces exerted by four disc brakes and rolling friction. Therefore, deceleration of the vehicle and stopping time can be calculated by following equations.

Total brake force,

$$
\mathrm{F}_{\mathrm{t}}=4 \times \mathrm{F}_{\mathrm{fd}}+\mathrm{F}_{\mathrm{fr}}
$$

By considering minimum wheel locking force above calculations were done and calculated values of the stopping time and distance as shown in Table 2. 


\begin{tabular}{|l|l|}
\hline Speed of vehicle $(\mathrm{m} / \mathrm{s})$ & 30 \\
\hline Friction Force on Each Disc $(\mathrm{N})$ & 5576.85 \\
\hline Total Braking Force $(\mathrm{N})$ & 9253.320945 \\
\hline Deceleration $\left(\mathrm{m} / \mathrm{s}^{2}\right)$ & 7.711100787 \\
\hline Stopping Time $(\mathrm{s})$ & 3.890495122 \\
\hline
\end{tabular}

Table 2: Calculation for initial speed of $30 \mathrm{~m} / \mathrm{s}$

\section{Model Development}

To carry out the analysis of the disc brake rotor, disc brake rotor of commercial automobile vehicle is taken as a standard to validate the parametric model of the disc brake rotor. Dimensions of the rotor are measured from the existing vehicle. Modeling and analysis are done using ANSYS. In order to study the effect of various parameters parametric modeling is done.

\subsection{Modeling of the disc brake rotor}

Parametric modeling of the disc brake rotors was done with the tool of ANSYS 17.1 known as Design Modeler.to reduce the number of nodes and elements $1 / 8^{\text {th }}$ geometry with symmetry was considered for analysis. Solid and cross-drilled disc brake rotors consist the same amount of mass and same hub dimensions. In cross drilled disc material obtained from drilling holes is utilized to increase thickness of the disc as shown in Figure 3.

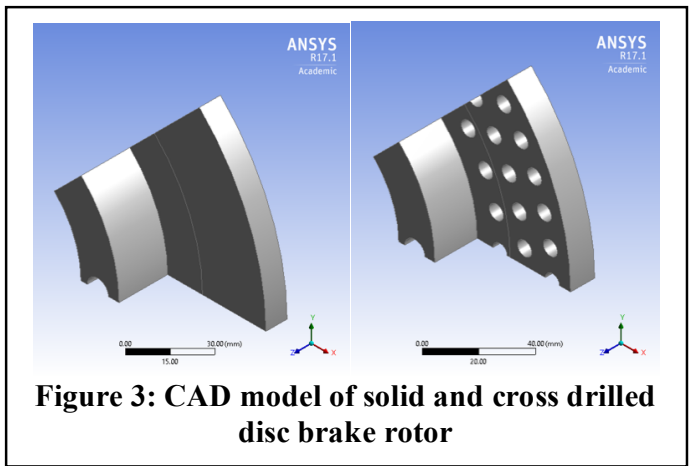

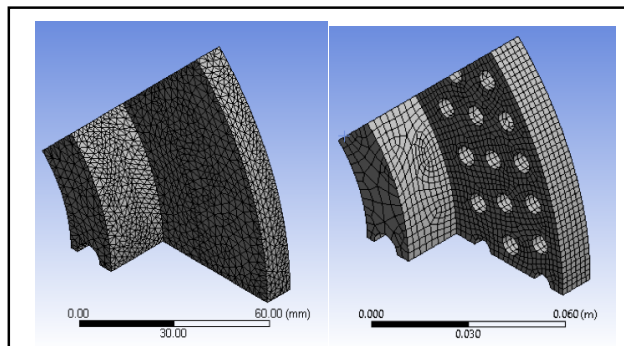

Figure 2: Mesh models of solid and cross drilled disc brake rotors

\section{Finite Element Analysis of disc brake rotor in ANSYS}

\section{1}

Analysis of disc brake rotor is done by considering single braking action from the speed of $30 \mathrm{~m} / \mathrm{s}$ and after application of brake, the vehicle comes to rest. For simplification of the model constant heat generation is assumed.

Heat transfer analysis is done considering the transient condition for 1000s. Braking action is done in the time of $0.1 \mathrm{~s}$ to $4.03 \mathrm{~s}$ as in the calculation of the brake time. In this duration, heat is generated at the rubbing surfaces which is calculated as follows.

Kinetic energy of the vehicle to be converted to heat,

$$
\Delta K E=\frac{M_{v} \times v^{2}}{2}=540000 \mathrm{~J}
$$

And Rate of heat generation, 


$$
Q_{g}=\frac{\Delta K E}{T S}=140911.4746 \mathrm{~W}
$$

Convective heat transfer coefficient is taken from the relations which are developed by Limpert (5) in his experimental studies for the solid disc brake rotor

\subsection{Analysis of solid disc brake rotor}

Maximum and minimum temperatures within the disc over the time range of analysis is plotted in Figure 4 and Figure 5. Temperature distribution in the disc at specific instances is shown in Figure 6.

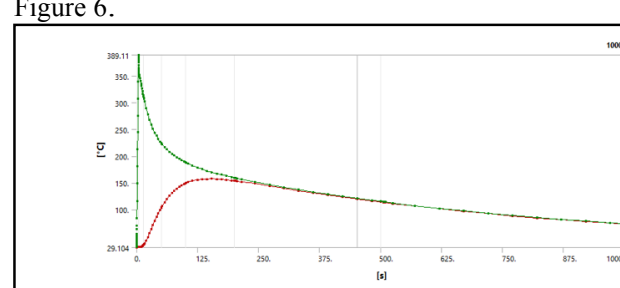

Figure 4: Min. and max. temperature v/s time for solid disc brake rotor over $1000 \mathrm{~s}$

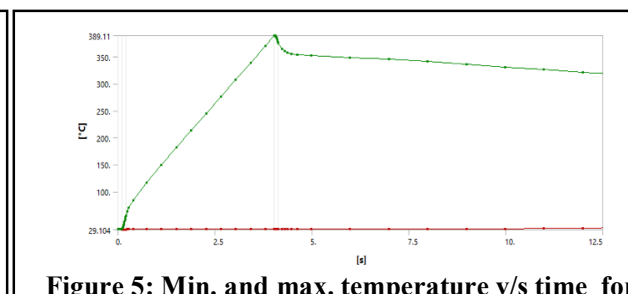

Figure 5: Min, and max, temperature v/s time for solid disc brake rotor over $12 \mathrm{~s}$

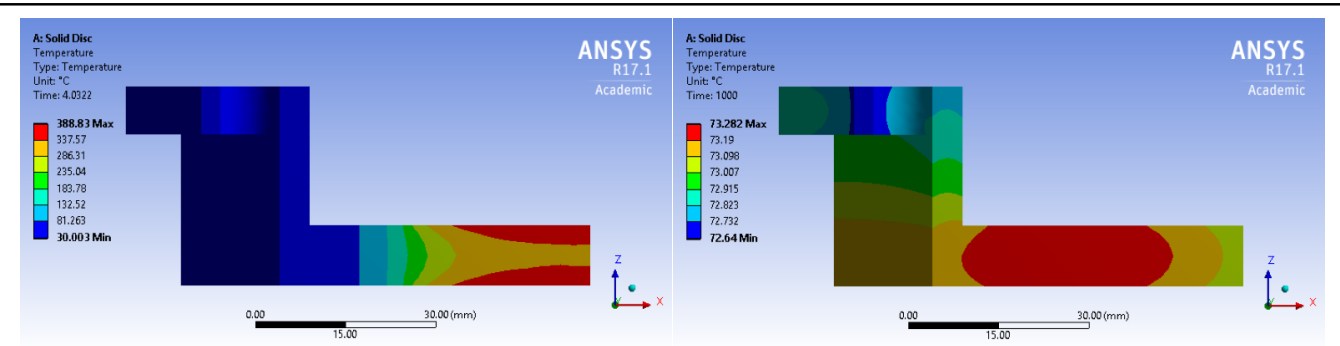

Figure 6: Temperature distribution in section of solid disc brake rotor at time 4.033s, $65 \mathrm{~s}$ and $1000 \mathrm{~s}$

Result interpretation:

$>$ Temperature value at the end of braking reaches significantly high values and suddenly drops as shown in Figure 5. It is due to conduction of heat from the heating surfaces in the direction of thickness. This is about $15 \%$ of temperature drop which occurs in less than $1 \mathrm{~s}$ of time.

$>$ Heat is transferred by conduction and convection both during first 200s as can be seen from Figure 4. After that, the temperature difference within the disc becomes very less and most of the heat is dissipated by convection.

\subsection{Analysis of cross drilled disc brake rotor}

Maximum and minimum temperatures within the disc over the time range of analysis is plotted in Figure 7 and Figure 8. Temperature distribution in the disc at specific instances is shown in Figure 9. 


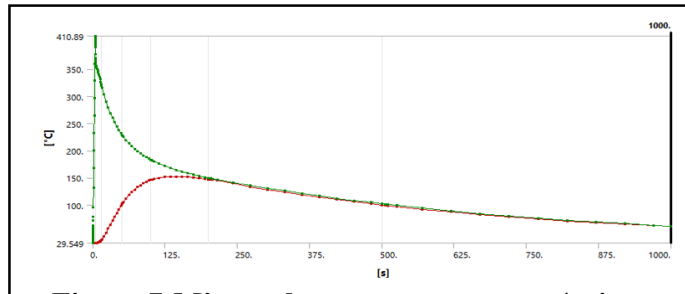

Figure 7:Min. and max. temperature v/s time for cross drilled disc brake rotor over 1000s

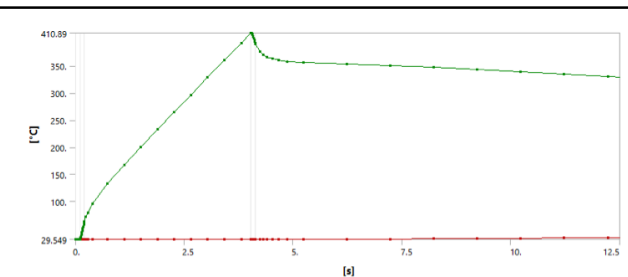

Figure 8: Min. and max. temperature v/s time for cross drilled disc brake rotor over $12 \mathrm{~s}$

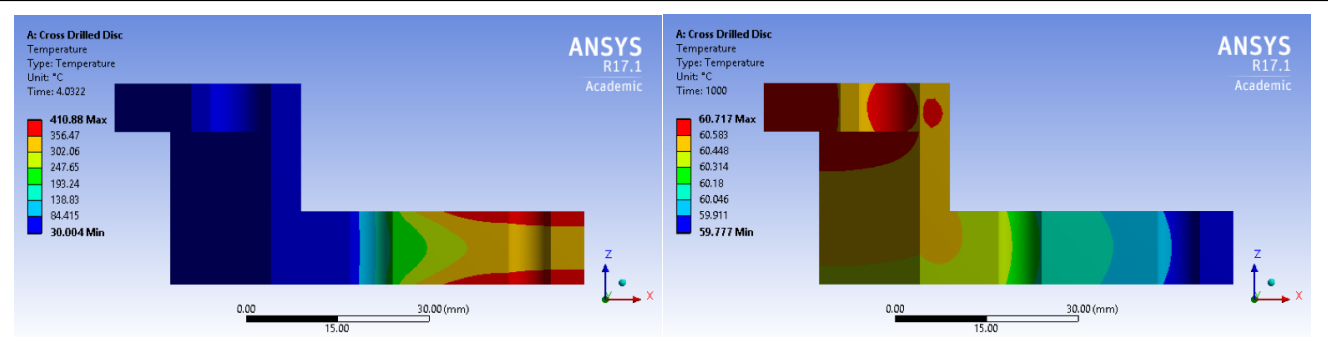

Figure 9: Temperature distribution in section of cross drilled disc brake rotor at time 4.033s, $65 \mathrm{~s}$ and $1000 \mathrm{~s}$

Result interpretation:

$>$ Cross drilled brake reaches higher value of temperature at $4.03 \mathrm{~s}$ compared to solid disc brake as shown in Figure 9. because in this rotor less rubbing area is available as number of holes are drilled on the surface.

$>$ In time range of $4.03 \mathrm{~s}$ to $65 \mathrm{~s}$ cross drilled disc has higher temperature than solid disc brake rotor as in Figure 9 because cross drilled brake rotor has holes in the conducting path and conduction is dominant in this time period.

$>$ From time $65 \mathrm{~s}$ to $1000 \mathrm{~s}$ this rotor has lower values of temperature than solid rotor as there is more surface area to dissipate heat by convection as shown in Figure 9.

\section{Conclusions}

$>$ Percentage reduction of conduction temperature drop can be improved by increasing the thickness of rotor.

$>$ Time taken for removing heat from is much high. It refers that several consecutive braking applications can increase the temperature at much higher values.

$>$ From the comparison of both rotors we can conclude that if the average braking cycle is short, solid disc brake rotor is advantageous and if the average braking cycle is long cross drilled disc brake rotor is more advantageous. 


\section{References}

1. Ihm, Mark. Introduction to Gray Cast Iron Brake Rotor Metallurgy. [Society of Automotive Engineers] s.1. : TRW Automotive,.

2. Auto, Auto Parts \& Systems, Brakes. How stuff works. [Online] [Cited: 12 02, 2016.] http://auto.howstuffworks.com/auto-parts/brakes/.

3. Material selection method in design of automotive brake disc. Maleque, Md, S. Dyuti, and Md Rahman. 2010, Proceedings of the World Congress on Engineering, pp. 1196-1201.

4. Cooling analysis of disc brake rotors. Limpert, R. SAE Paper 751014, 1975.

5. The thermal performance of automotive disc brakes. Limpert, R. SAE Paper 750873, 1975.

6. Limpert, Rudolf. Brake design and safety . s.l. : Society of Automotive Engineers, 1992.

7. Analysis of automotive disc brake cooling characteristics. Voller, G.P., Tirovic, M., Gibbens, P. D11902, s.l. : IMechE, 2003.

8. Analysis of a Ventilated Disc Brake Rotor Using CFD to improve its thermal performance. KaruppaRaj, Dr Thundil. Vellore : s.n., 2013.

9. Temperature and Thermal Stresses of Vehicles Gray Cast Brake. Belhocine, A., and M. Bouchetara. 2013, Journal of applied research and technology, pp. 674-682.

10. Thermal analysis of a solid brake disc. Belhocine, Ali, and Mostefa Bouchetara. 2012, Applied Thermal Engineering 32 , pp. 59-67. 